Document downloaded from:

http://hdl.handle.net/10251/55702

This paper must be cited as:

Llorca Garcia, C.; Moreno Chou, AT.; Lenorzer, A.; Casas, J.; García García, A. (2015). Development of a new microscopic passing maneuver model for two-lane rural roads. Transportation Research Part C: Emerging Technologies. 52:157-172. doi:10.1016/j.trc.2014.06.001.

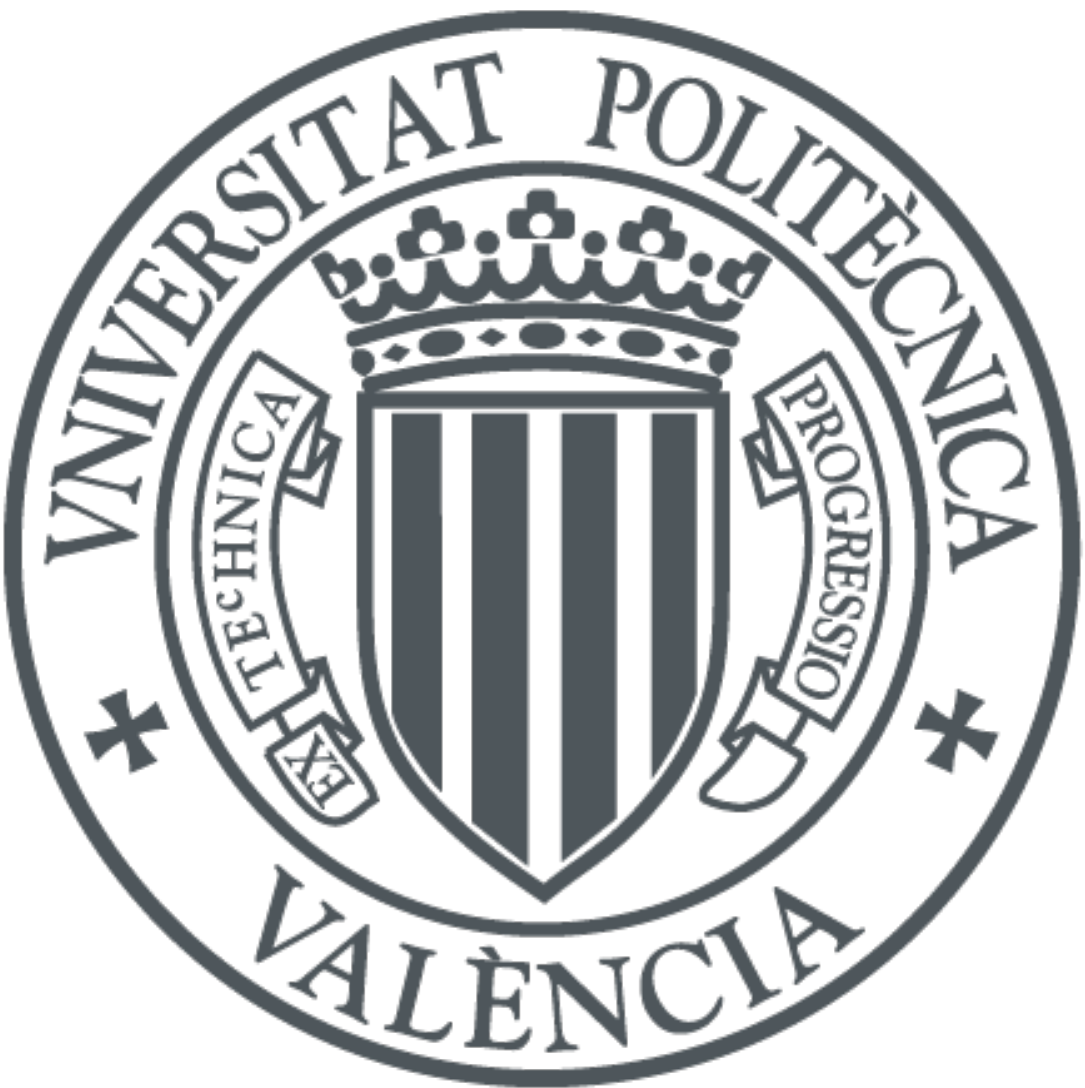

The final publication is available at

http://dx.doi.org/10.1016/j.trc.2014.06.001

Copyright Elsevier

Additional Information 


\title{
Development of a new microscopic passing maneuver model for two-lane rural roads
}

\author{
Carlos Llorca \\ PhD Candidate \\ Highway Engineering Research Group \\ Universitat Politècnica de València \\ Camino de Vera s/n 46022 - Valencia (Spain) \\ carlloga@cam.upv.es \\ Ana Tsui Moreno \\ PhD Candidate \\ Highway Engineering Research Group \\ Universitat Politècnica de València \\ Camino de Vera s/n 46022 - Valencia (Spain) \\ anmoch@cam.upv.es
}

\author{
Annique Lenorzer \\ $\mathrm{PhD}$ \\ Research and Development Department \\ Transport Simulation Systems \\ Passeig de Gràcia 12, 08007 - Barcelona (Spain) \\ annique@aimsun.com
}

\section{Jordi Casas}

$\mathrm{PhD}$, Director

Research and Development Department

Transport Simulation Systems

Passeig de Gràcia 12, 08007 - Barcelona (Spain)

casas@aimsun.com

\author{
Alfredo Garcia \\ Professor \\ Highway Engineering Research Group \\ Universitat Politècnica de València \\ Camino de Vera s/n 46022 - Valencia (Spain)
}

agarciag@tra.upv.es 


\section{Abstract}

Microsimulation is a useful tool to analyze traffic operation. On two-lane highways, the complexity of passing and the interaction with oncoming traffic requires specific models. This study focused on the development of a passing desire, decision and execution model. Results of the observation of 1,752 maneuvers on 10 rural roads in Spain were used for this development. The model incorporated the effect of new factors such as available sight distance, delay and remaining travel time until the end of the highway segment. Outputs of the model were compared to observed data: firstly, individual passing maneuvers; secondly, traffic flow, percent followers and number of passing maneuvers in four single passing zones with two different traffic levels. The model was validated in four alternative passing zones.

\section{Highlights}

- Specific characteristics of two-lane roads require special microsimulation models.

- The interaction with oncoming vehicles makes passing a complex task.

- This study developed a new passing model for Aimsun software, including 3 steps: desire, decision and execution.

- More than 1,750 video-recorded passing maneuvers to calibrate the new model.

- The new model incorporated the effect of sight distance, delay and multiple passing maneuvers.

\section{Keywords}

Microsimulation, Two-lane highway, Passing maneuver, Passing gap acceptance 


\section{Introduction and Background}

Microsimulation of traffic requires the description of the movement of each individual vehicle in the traffic stream. Therefore, microscopic models include several components to represent the maneuvers performed by individuals, such as acceleration, deceleration, car following or lane changing (Barceló, 2010).

Common applications of microscopic modelling of traffic are, among others, the study of signalized and unsignalized intersections (Stevanovic et al., 2013), roundabouts (Ištoka Otković et al., 2013), emission estimations (Jie et al., 2013), passing and climbing lanes (Valencia and Garcia, 2010), or evaluation of intelligent transportation systems (ITS) and cooperative systems (Hegeman et al, 2008).

The application of microsimulation to analyze two-way two-lane rural roads is also possible. However, the interaction with opposing traffic flow implies the development of specific passing models. On two-lane rural roads, passing maneuver allows faster drivers to pass slower vehicles and drive at their own desired speeds. This maneuver has an important effect on the level of service and contributes increasing the capacity of these roads (Transportation Research Board, 2010).

Passing is only possible on certain sections where available sight distance exceeds a minimum passing sight distance $(P S D)$ requirement determined by standards. Therefore, there is an effect of geometric design on the frequency and characteristics of passing maneuver. However, this maneuver depends mainly on the human factor, since it involves several complex decisions. Traditionally, the following stages explain passing driver's behavior:

- Passing desire: driver's desire to pass or to keep on following the slower vehicle.

- Passing decision (gap acceptance): for drivers who desired to pass, their decision to accept or reject a passing opportunity (named gap) in the opposing traffic.

- Passing execution: for drivers who accepted a gap, the passing performance and the decision to complete or abort the maneuver, before reaching the critical point (point of no return).

The complexity and higher dispersion of passing process is visible in many observational studies (Polus et al, 2000, Carlson et al, 2005, Harwood et al, 2010, Llorca et al. 2013a, Llorca et al, 2013b). Consequently, many researchers considered the use of alternative approaches to analyze two-lane roads, such as driving simulators (Jenkins and Rillet, 2004, Farah and Toledo, 2010, Farah, 2011) or microscopic modelling. The following section focuses on the existing microscopic passing models.

\subsection{Existing models}

There have been previous research focused on the development of passing models. However, their level of detail, their validation or their field of application are not homogeneous.

The Interactive Highway Safety Design Model (IHSDM) includes a passing model as part of the Traffic Analysis Module (TAM, previously named TWOPAS). This model has been used to analyze average travel speeds (ATS) and percent time spent following (PTSF) (Bessa and Setti, 2011), or the addition of climbing lanes to facilitate passing (Valencia and Garcia, 2010). Harwood et al. (2010) used this model to demonstrate that short passing zones (under $240 \mathrm{~m}$ ) did not contribute to improve the level of service of rural roads. Authors did not validate TAM with this study, assuming TAM initial calibration based on 1970's data (Harwood et al. 1999). 
Several authors detected limitations in TAM. According to Li and Washburn (2011), this model does not provide the ability to include signalized intersection within the modeled highway. Kim and Elefteriadou (2010) stated that the program stalls when traffic volume exceeds 1,700 vph.

Li and Washburn (2011) developed a passing model for CORSIM software. The CORSIM model includes the following steps: passing desire, depending on tolerable and desired speed, as well as impatience; and passing decision and execution: based on estimated PSD according to the Manual on Uniform Traffic Control Devices (FHWA, 2003) and Harwood et al. (2010), also included in AASHTO Green Book (2011). CORSIM can take into account no-passing zone marking and opposing traffic, although the effect of available sight distance is not considered. Although this model increased the level of detail of TAM, there is still neither any validation nor calibration with field data.

Kim and Elefteriadou (2010) developed a microsimulation model to determine two-lane highways capacity. This model assumes a consistent and homogenous driver behavior. To consider passing, driver's desired speed should be $8 \mathrm{~km} / \mathrm{h}$ higher than the leading vehicle. TWOSIM uses the Green Book (2004) PSD values. This model was verified comparing results of ATS and PTSF with TAM model. The authors also compared passing times with field data from other authors. Authors obtained a capacity up to $2100 \mathrm{vph}$ for two-lane roads applying this model to generated road segments. Previously, Dey et al. (2008) described another passing microsimulation model. Those authors used also the model to evaluate capacity of two-lane rural roads. The results of capacity ranged between 2400 and 3000 passenger car units (PCU). However, the only validation process of this model was the comparison of arrival distributions and spot speeds with real data.

Hegeman et al (2008) used the microsimulation model RutSim to test the effect of driver's assistant systems. This model was an evolution of the VTI model, developed by Tapani (2005). VTI was validated at a microscopic level, although the frequency and characteristics of passing maneuvers were not tested. Other models that have been used mainly in research studies were LASI (Brilon and Brannolte, 1977), TRARR (Hoban et al, 1991), and Ghods (2013).

Other passing studies (such as El Khoury and Hobeika, 2010, Farah and Toledo, 2010) modeled single passing maneuvers or binary choice processes, respectively, but they are not strictly microsimulation models. Lastly, Jenkins and Rillet (2004) combined a microscopic model (not able to represent passing maneuvers) with a driving simulator, while the microsimulator generated the rest of traffic. A sample of drivers performed passing maneuvers in a controlled driving simulator experiment. However, those studies cannot be applied to evaluate the traffic performance on different real rural road scenarios.

As seen in the literature review, there are different approaches to microscopic passing maneuver models. They include different parameters and assumptions, which are rarely justified by the observation of the phenomenon. Besides, most of them are still not validated with detailed observations of passing maneuvers, and may provide unrealistic results under conditions other than the tested. The complexity of modeling two-lane rural roads, compared to other facilities, such as freeways, and their lower traffic volume may explain why those models are generally only applied in research studies.

The conclusion of the literature review is the necessity of calibrating and validating a passing maneuver model, as part of a microsimulation software. With this contribution, microsimulation tools might be also applied in operational analyses involving two-way two-lane rural road segments. 


\section{Objectives}

The aim of this paper is the development and calibration of a passing maneuver model in Aimsun microsimulation software (Transport Simulation Systems, 2013). This main goal is divided into the following objectives:

- Development and implementation of a passing maneuver model and a modified carfollowing model in the Aimsun software.

- Microscopic scale calibration: analysis and comparison of individual passing decision and individual passing execution, based on data of maneuvers observed from an instrumented vehicle.

- Macroscopic scale calibration: analysis and comparison of basic performance measures: input traffic flow, percent followers and number of passes in four passing zones (PZ) of an observed highway, based on data obtained with static video cameras.

- Validation of the model in four passing zones other than the used in the previous calibration.

\section{Observation of passing maneuvers}

Both development, calibration and validation of the model depended on observational data. A field study obtained data from 1,752 maneuvers using two methodologies on 10 two-lane road segments. Both methods are a further development from previous research work of authors (Llorca and Garcia, 2011, Llorca et al. 2013a). They consisted on video recording of passing maneuvers without the intervention of observers.

The first methodology (named static) (Llorca and Garcia, 2011) consisted in recording videos from external fixed positions on 24 passing zones in eight road segments. The mobile traffic laboratory of the Universitat Politècnica de València (Spain) was parked next to the highway. This equipment is composed of six digital video cameras installed on the top of an elevator platform. A wireless network facilitates adjusting zoom and focus of video cameras, in order to collect video images of the entire passing zone with uniform quality. In two of the locations, the mobile traffic laboratory was substituted by conventional video cameras.

The second methodology (named dynamic) (Llorca et al, 2013b) used two instrumented vehicles. The objective was for other vehicles to pass the instrumented vehicle, collecting data of these maneuvers and the entire following process. The vehicle was driven along six road segments. In five of the segments, the static method was also applied, in order to compare passing maneuvers, to ensure that the dynamic method did not affect driver's behavior. The result of the comparison showed no differences between both methods on passing times.

The instrumented vehicle was equipped with four VBOX cameras, covering rear, left side and front of the vehicle. Two laser rangefinders measured distance gaps between the instrumented car and other vehicles behind and in front of it. Measuring systems are very small and are installed inside the car (cameras and recording units) or in front and rear bumpers (rangefinders). No following driver performed unexpected maneuvers, like following without pass or with longer headways.

A $10 \mathrm{~Hz}$ GPS tracker connected to a VBOX unit provided the position and speed of the instrumented vehicle. The speed of the instrumented vehicle was selected according to the observations of the static methodology, which had been previously carried out. In those observations, speed of a sample of impeding vehicles was measured using video recordings. 
Therefore, the instrumented vehicle speed was set as the $15^{\text {th }}$ percentile of speed of impeding vehicles at this location (measured with the static methodology), neither too fast nor too slow.

Table 1 and Figure 1 summarize data collection.

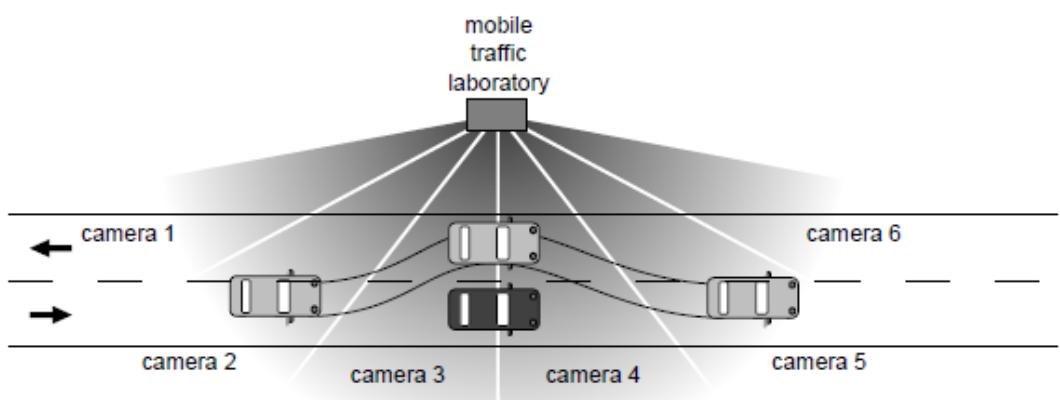

(a) Static data collection

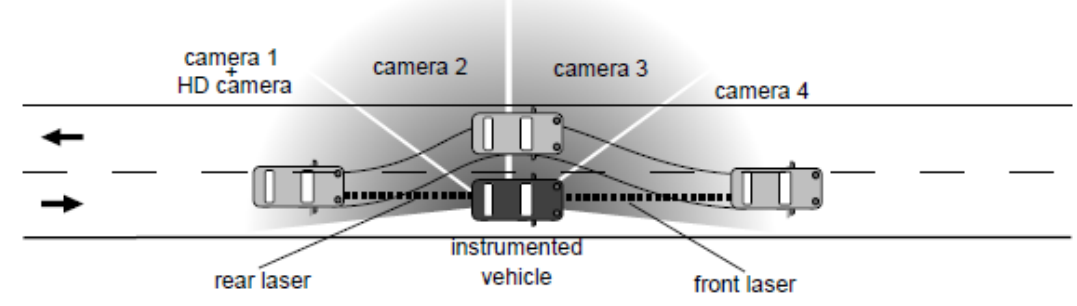

(b) Dynamic data collection

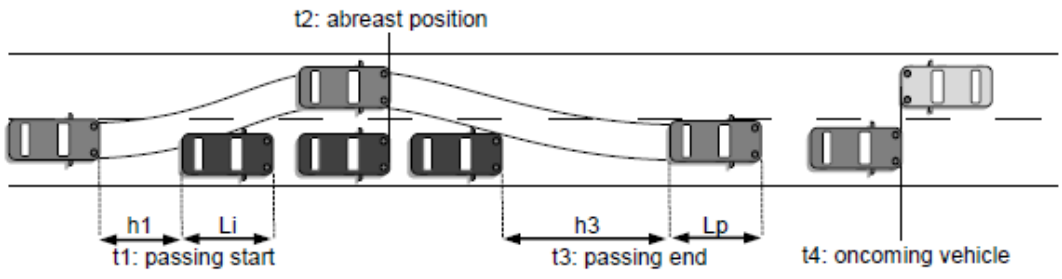

(c) Passing maneuver variables

Figure 1. Field study layout and description of the passing maneuver 


\begin{tabular}{|c|c|c|c|c|}
\hline \multirow[b]{2}{*}{ Road segment } & \multicolumn{4}{|c|}{ Static methodology } \\
\hline & $\begin{array}{l}\text { Design speed } \\
(\mathrm{km} / \mathrm{h})\end{array}$ & $\begin{array}{l}\text { Speed limit } \\
(\mathrm{km} / \mathrm{h})\end{array}$ & $\begin{array}{l}\text { Number of } \mathrm{PZ} \\
\text { analyzed (total } \\
\text { number of } \mathrm{PZ} \text { in } \\
\text { the segment) }\end{array}$ & $\begin{array}{l}\text { PZ length range } \\
(\mathrm{m})\end{array}$ \\
\hline $1-C V-35$ & 120 & 100 & $6(10)$ & 780 to 1,855 \\
\hline $2-C V-50$ & 80 & 100 & $4(17)$ & 600 to 990 \\
\hline $3-\mathrm{CV}-50 \mathrm{ii}$ & 90 & 100 & $4(12)$ & 265 to 285 \\
\hline $4-C V-37$ & 70 & 100 & $2(2)$ & 550 to 560 \\
\hline $5-C V-25$ & 80 & 100 & $2(10)$ & 1,000 \\
\hline $6-C V-35 \mathrm{iii}$ & 70 & 100 & $2(10)$ & 540 to 520 \\
\hline $7-N-225$ & 100 & 100 & $4(13)$ & 265 to 1,270 \\
\hline \multirow[t]{2}{*}{$8-C V-405$} & 70 & 80 & $2(22)$ & 895 \\
\hline & \multicolumn{4}{|c|}{ Dynamic methodology } \\
\hline Road & $\begin{array}{c}\text { Design speed } \\
(\mathrm{km} / \mathrm{h})\end{array}$ & & Number of PZ & $\begin{array}{l}\text { PZ length range } \\
(\mathrm{m})\end{array}$ \\
\hline $1-N-225$ & 100 & 100 & $13(13)$ & 265 to 1,284 \\
\hline $2-C V-35$ & 120 & 100 & $10(10)$ & 435 to 1,855 \\
\hline $3-C V-50$ & 80 & 100 & $12(12)$ & 268 to 1,215 \\
\hline $4-C V-50 \mathrm{ii}$ & 90 & 100 & $17(17)$ & 228 to 1,127 \\
\hline $5-C V-415$ & 70 & 90 & $18(18)$ & 100 to 1,250 \\
\hline $6-C V-405$ & 70 & 80 & $22(22)$ & 103 to 904 \\
\hline
\end{tabular}

Table 1. Data collection sites

This field study has provided data of 1,752 passing maneuvers: 1,292 using the static methodology during 36 hours of observations; and 460 using the dynamic methodology. The dynamic methodology used as instrumented vehicle one light vehicle (414 passes in 18 hours) and one truck (46 passes in 8 hours).

Static observations characterized passing frequency, measured in passes per hour (Moreno et al., 2013). Hourly traffic volumes, as well as percent of followers entering the observed passing zones were also registered. For this count, one vehicle was following a leader vehicle if headway between them was less than $3 \mathrm{~s}$, according to the Highway Capacity Manual criterion (Transportation Research Board, 2010). Average travel speeds were also measured. On the other hand, the dynamic methodology allowed the detailed characterization of passing decisions and passing dynamic (Figure 1), including accepted and rejected gaps. The static methodology was necessary to evaluate the operation of two-lane segments, because of the absence of any intervention of researchers, while the dynamic method provided a higher level of detail to characterize individuals' passing decision and execution.

Table 2 summarizes the variables observed in data collection. The count of each variable may be lower than the total amount of maneuvers, due to measurement inaccuracy or missing values. Besides, the more detailed characterization was available only for simple passes (one impeding vehicle). 


\begin{tabular}{|c|c|c|c|c|c|c|}
\hline & \multicolumn{6}{|c|}{ Static methodology - traffic flow scale } \\
\hline Variable & Code (Units) & $\mathrm{N}$ & Minimum & Mean & SD & Maximum \\
\hline Number of passes & $\begin{array}{c}\mathrm{NP} \\
\text { (passes/hour) }\end{array}$ & 210 & 0 & 16 & 12 & 51 \\
\hline $\begin{array}{c}\text { Hourly traffic volume } \\
\text { (one direction) }\end{array}$ & V (vph) & 210 & 84 & 210 & 108 & 472 \\
\hline Percent followers* & $\% \mathrm{FV}$ & 210 & $4 \%$ & $35 \%$ & $14 \%$ & $73 \%$ \\
\hline $\begin{array}{c}\text { Percent heavy } \\
\text { vehicles** }\end{array}$ & $\% \mathrm{HV}$ & 210 & $0 \%$ & $16 \%$ & $12 \%$ & $44 \%$ \\
\hline & \multicolumn{6}{|c|}{ Dynamic methodology - individual scale (light vehicle) } \\
\hline Passing vehicle length & $L_{p}(m)$ & 414 & 3.5 & 4.5 & 1.0 & 5.5 \\
\hline $\begin{array}{c}\text { Number of impeding } \\
\text { vehicles }\end{array}$ & Number i & 414 & 1 & 1.2 & 0.4 & 3 \\
\hline Passing time & $\mathrm{PT}=\mathrm{t}_{3}-\mathrm{t}_{1}(\mathrm{~s})$ & 314 & 4.2 & 7.1 & 1.9 & 16.5 \\
\hline $\begin{array}{l}\text { Impeding vehicle } \\
\text { average speed }\end{array}$ & $\mathrm{V}_{\mathrm{i}}(\mathrm{km} / \mathrm{h})$ & 314 & 50 & 66 & 9.0 & 100 \\
\hline $\begin{array}{l}\text { Passing vehicle } \\
\text { average speed }\end{array}$ & $V_{p}(k m / h)$ & 314 & 53 & 86 & 12.8 & 147 \\
\hline $\begin{array}{c}\text { Average speed } \\
\text { difference }\end{array}$ & $\mathrm{dV}(\mathrm{km} / \mathrm{h})$ & 314 & 3.5 & 20.3 & 8.6 & 74.3 \\
\hline $\begin{array}{c}\text { Passing vehicle relative } \\
\text { speed at end }\end{array}$ & $V p_{3}(k m / h)$ & 215 & 13 & 25 & 7.7 & 38 \\
\hline Opposing flow gap & $\operatorname{GAP}(s) * * *$ & 1,621 & 0.3 & 8.5 & 8.4 & 40.0 \\
\hline \multirow[t]{2}{*}{$\begin{array}{c}\text { Time until crossing } \\
\text { with opposing vehicle }\end{array}$} & $t_{4}-t_{3}(s)$ & 174 & 0.84 & 10.5 & 9.2 & 40.0 \\
\hline & \multicolumn{6}{|c|}{ Dynamic methodology - individual scale (heavy vehicle) } \\
\hline Passing vehicle length & $\operatorname{Lp}(\mathrm{m})$ & 46 & 3.5 & 4.5 & 1.0 & 5.5 \\
\hline $\begin{array}{c}\text { Number of impeding } \\
\text { vehicles }\end{array}$ & Number i & 46 & 1 & 1 & 0 & 1 \\
\hline Passing time & $\mathrm{PT}=\mathrm{t}_{3}-\mathrm{t}_{1}(\mathrm{~s})$ & 46 & 5.7 & 9.1 & 1.9 & 11.4 \\
\hline $\begin{array}{l}\text { Impeding vehicle } \\
\text { average speed }\end{array}$ & $\mathrm{V}_{\mathrm{i}}(\mathrm{km} / \mathrm{h})$ & 46 & 60.5 & 67.9 & 4.7 & 74.8 \\
\hline $\begin{array}{l}\text { Passing vehicle } \\
\text { average speed }\end{array}$ & $V_{p}(k m / h)$ & 46 & 76.4 & 88.5 & 6.3 & 102.9 \\
\hline $\begin{array}{c}\text { Average speed } \\
\text { difference }\end{array}$ & $\mathrm{dV}(\mathrm{km} / \mathrm{h})$ & 46 & 10.9 & 21.4 & 7.6 & 31.7 \\
\hline $\begin{array}{c}\text { Passing vehicle relative } \\
\text { speed at end }\end{array}$ & $V p_{3}(k m / h)$ & & & $* * * *$ & & \\
\hline Opposing flow gap & $\operatorname{GAP}(\mathrm{s})^{* * *}$ & 159 & 0.2 & 11.2 & 10.4 & 50.8 \\
\hline $\begin{array}{c}\text { Time until crossing } \\
\text { with opposing vehicle }\end{array}$ & $t_{4}-t_{3}(s)$ & 39 & 0.8 & 9.8 & 8.4 & 35.9 \\
\hline \multicolumn{7}{|c|}{$\begin{array}{l}* \text { percent follower is the percentage of vehicles following (headway under } 3 \mathrm{~s} \text { ) over the total number } \\
\text { of vehicles entering the passing zone during } 1 \text { hour. } \\
* * \text { percent heavy vehicles is the percentage of vehicles over } 3,500 \mathrm{~kg} \text { during } 1 \mathrm{~h} \text {. } \\
* * * \text { either accepted or rejected } \\
* * * * \text { not measured }\end{array}$} \\
\hline
\end{tabular}

In addition to passing maneuver characterization, speed measurements were carried out at several locations in free-flow conditions. This had the objective of measuring desired speeds. A laser device Laser Technology Inc. T100/200 was used for the data collection. This provided the desired speed distribution (for either light vehicles or heavy vehicles), considering only those vehicles driving with a following headway higher than $10 \mathrm{~s}$. Speeds were measured at the middle point of tangents long enough. 


\section{Model Development}

The main objective of this study was the development of a model to simulate passing maneuvers on two-lane, two-way rural roads. This model, implemented in Aimsun 8.0.3, covers the desire, decision and execution process of passing maneuvers. This relied on 14 parameters, defined specifically for the two-lane highways model.

\subsection{Parameters}

The 14 model parameters are associated with the experiment, the vehicle type or the section Aimsun editors. An Aimsun experiment is a group of simulations under certain fixed conditions: an input traffic volume and composition, a network structure and characteristics, and the definition of simulation models. The parameters that affect the entire experiment are:

- Delay time threshold for passing decision (delayTh) (s)

- Minimum speed difference threshold $(\operatorname{mind} V)(\mathrm{km} / \mathrm{h})$

- Maximum speed difference threshold ( $\operatorname{maxdV})(\mathrm{km} / \mathrm{h})$

- Maximum rank in the platoon to desire passing (maxRank) (vehicles)

- Number of simultaneous passes allowed (maxSimul) (passes)

- Delay between simultaneous passes (delaySimul) (s)

- Sensitivity factor for reduced car-following (RCF)

- Passing vehicle speed enhancement (PVSE)

- Speed difference threshold for enhanced passing vehicle speed (PVSETh) $(\mathrm{km} / \mathrm{h})$

- Remaining time to the end of the highway segment threshold (remainingtimeTh) (s)

Traffic demand in Aimsun may be divided into several vehicle types. The parameter that affects a particular vehicle type are:

- Safety margin for passing maneuver (safetymargin), defined by its minimum, maximum, mean and standard deviation values (values in s)

Each highway geometric element corresponds to an Aimsun section. A section is a highway segment with uniform characteristics. The parameters that affect a single section are:

- Mirror section identification (MirrorID)

- Available sight distance at the end of the passing zone (ASD) (m)

- Sight distance factor (SDfactor)

The description and use of each parameter will be explained in the following sections.

\subsection{Network generation}

The edition of a two-lane, a two-way section is achieved by creating a two-lane section, generating the section in opposite direction and editing the model attributes. Therefore, each geometric element (in each direction) of the two-lane highway is defined by a single Aimsun section. Each section interacts with a mirror section, which represents the opposing lane.

Both opposing sections are linked by the MirrorID parameter. When a valid MirrorID number is entered, the mirror section is shifted and resized below the edited section. The available sight distance at a passing zone is defined by the parameter ASD. This value corresponds to the available sight distance at the end of the passing zone. Available sight distance decreases linearly from the starting point of the passing zone (where is equal to $A S D+$ Passing zone length) to the ending point of it (where is equal to $A S D$ ). 


\subsection{Description of the passing model}

The possibility to pass is considered for the vehicles that are in queue. Each vehicle that cannot reach its desired speed due to downstream traffic conditions is considered to be in queue. The queue leaders are identified as the vehicles triggering the queues.

\subsubsection{Desire}

For each vehicle in queue, the passing desire is evaluated based on four characteristics:

- Time spent following (delay) (s)

- Difference between the desired speed and the actual speed of the immediate leader $(d V)(\mathrm{km} / \mathrm{h})$

- Rank in the queue (rank)

- Remaining travel time to the end of the highway segment (remainingtime) (s)

Figure 2 shows the passing desire as a function of time spent following (delay) and speed difference $(d V)$. If the speed difference $d V$ is higher than $\max d V$, the vehicle desires to pass immediately after entering the queue (flying pass). On the other hand, if the speed difference $d V$ is lower than maxdV, the passing vehicle desires to pass after spending a certain time following the leading vehicle. The minimum delay time to consider passing increases if the speed difference decreases, until a minimum speed difference (mindV), when it reaches delayTh. No passing is desired if speed difference is lower than mindV.
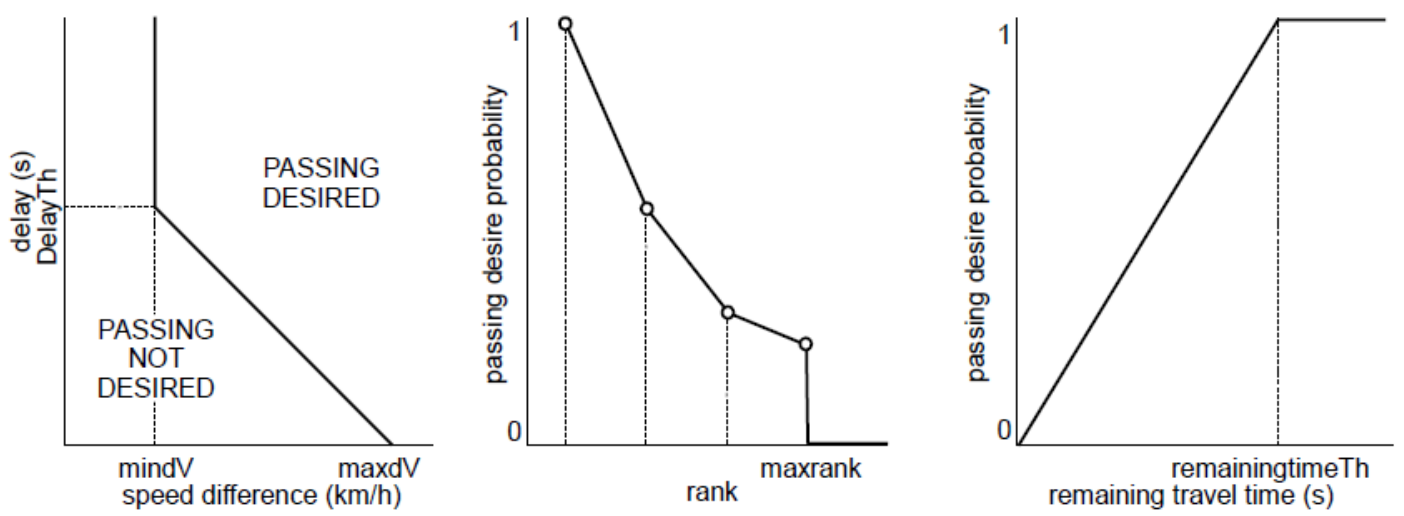

Figure 2. Passing desire

Passing desire may be reduced by the rank in the queue and the remaining time until the end of the highway segment. The desire probability decreases with the rank in the queue, as shown in Figure 2. On the other hand, the desire probability decreases also when the vehicle is reaching the end of the highway segment, as explained in the Figure 2. The definition of remainimgtimeTh was necessary to represent an important reduction of passing demand in the last passing zones of a highway segment. This was observed thanks to the dynamic methodology, and was especially significant when the next segment was a divided road.

If the passing maneuver is desirable, the vehicle applies a car-following with a reduced safety gap using the car-following distance reduction factor parameter (RCF). Modified car following applies Gipps model (Gipps, 1981) according to the equation 1. 


$$
V_{f}(t+d t)=b_{f} d t+\sqrt{\left(b_{f} d t\right)^{2}-b_{f}\left[2\left(x_{l}(t)-x_{f}(t)-l_{l}-s_{f}\right)-V_{f}(t)-\frac{V_{l}^{2}(t)}{R C F \cdot b_{l}}\right]}
$$

Where:

- $\quad x_{f}, V_{f}$, and $b_{f}$ : position, speed and normal deceleration of the follower.

- $\quad x_{l}, V_{l}$ and $b_{l}$ : position, speed and normal deceleration of the leader.

- $S_{f}$ : headway at rest.

- $L_{l}$ : length of the leader vehicle.

- RCF: sensitivity factor. The Gipps model assumes RCF equal to 1 in normal conditions, while the modified car-following is applied with $R C F<1$.

\subsubsection{Decision}

The decision to initiate the passing maneuver includes the verification that no solid line forbids passing. In case other vehicles are currently passing the leading vehicle, it takes into account whether simultaneous passing is allowed, following the number of simultaneous passes allowed (maxSimul), and whether the delay between simultaneous overtaking (delaySimul) is respected.

If allowed, the passing decision is evaluated. In case the speed difference between the desired speed and the actual speed of the immediate leader is under the speed difference threshold for enhanced passing vehicle speed (PVESth), the vehicle will use an enhanced desired speed equal to the product of its desired speed and the passing vehicle speed enhancement factor (PVSE). This factor accounts for the possibility of travelling at a speed higher than driver's free-flow desired speed. This effect was detected from the observations and it is permitted, at least, by the Spanish traffic regulation.

To evaluate the passing decision, the following variables are calculated:

- Passing maneuver time (PT): duration of the maneuver (s), calculated assuming that the vehicle maintains a constant acceleration until it reaches its desired speed (or its enhanced passing speed) after which it maintains a constant speed.

- Time to collision (s) with the closest oncoming vehicle (TC): assuming that the oncoming vehicle keeps a constant speed. In case there is no oncoming vehicle, or if it is located further away than the available sight distance at the decision point, the model uses a fictitious vehicle located at the visibility edge. This will generate an oncoming-vehicle limited equivalent passing gap, where speed of opposing vehicle is random but centered in the opposing section speed limit.

- Time to sign (TS): time to no-passing marking or signing. It is the time (s) until the end of the passing zone.

The consideration of differences in simulated passing behavior between oncoming vehicle and sight distance-limited maneuvers was a consequence of the observational study. Drivers accepted shorter gaps when the oncoming vehicle was not visible (Llorca et al., 2012). For this reason, the SDfactor multiplies sight distance-limited gaps, resulting virtual longer sight distance-limited gaps; so, increasing the probability of acceptance, compared to oncoming vehicle-limited gaps. Therefore, only one gap acceptance model was developed and used. 
The vehicle will initiate the passing maneuver if it can be completed before the end of the passing zone and if the duration of the maneuver (PT) is less that the time to collision taking a safety margin defined by the safetymargin parameter (different for each vehicle).

\subsubsection{Execution}

Once the passing execution has been decided, the vehicle accelerates at its maximum acceleration until its desired speed (or its enhanced passing speed) is reached. The feasibility of the maneuver is re-evaluated at each simulation step during the passing maneuver. An additional variable is calculated in this step:

- $\quad$ Time required to abort $(A T)$ : is the time (s) the passing vehicle requires to decelerate and return to its own lane without passing the impeding vehicle. The critical point is the point where $P T$ is equal to $A T$.

Depending on the remaining passing time $(P T)$, the time to collision $(T C)$ and the time required to abort the maneuver $(A T)$ the vehicle will follow one of the five possible maneuver completions:

- The maneuver is not completed yet and there is no risk of collision (PT + safetymargin < $T C$ ): The vehicle keeps passing using a constant acceleration corresponding to its maximum acceleration of the vehicle (defined in the general Aimsun model) until it reaches its desired speed (or its enhanced passing speed). It then keeps passing at constant speed.

- The maneuver is not completed yet, there is a risk of collision and the vehicle has not yet reached the critical point $(P T+$ safetymargin $>T C$ and $P T>A T)$ : the vehicle aborts the passing maneuver. It pulls back into its original lane decelerating behind the vehicle it was trying to pass (deceleration rate is equal to emergency deceleration in the general Aimsun model).

- The maneuver is not completed yet and there is a risk of collision but not immediate and the vehicle has already reached the critical point $(P T+$ safetymargin $>T C, T C>$ $2 *$ Reaction time and $P T<A T)$ : the vehicle accelerates to complete the maneuver before collision (acceleration rate is equal to maximum acceleration of the vehicle).

- The maneuver is not completed yet, there is an immediate risk of collision and the vehicle has already reached the critical point $(P T+$ safetymargin $>T C, T C<2 *$ Reaction time and $P T<A T)$ : the vehicle accelerates to pull back into its original lane in front of the overtaken vehicle, forcing it to decelerate.

- The maneuver is completed ( $P T=0)$ : The vehicle pulls back in its original lane in front of the vehicle it was passing.

Figure 3 shows the model flowchart for passing desire, decision and execution. 


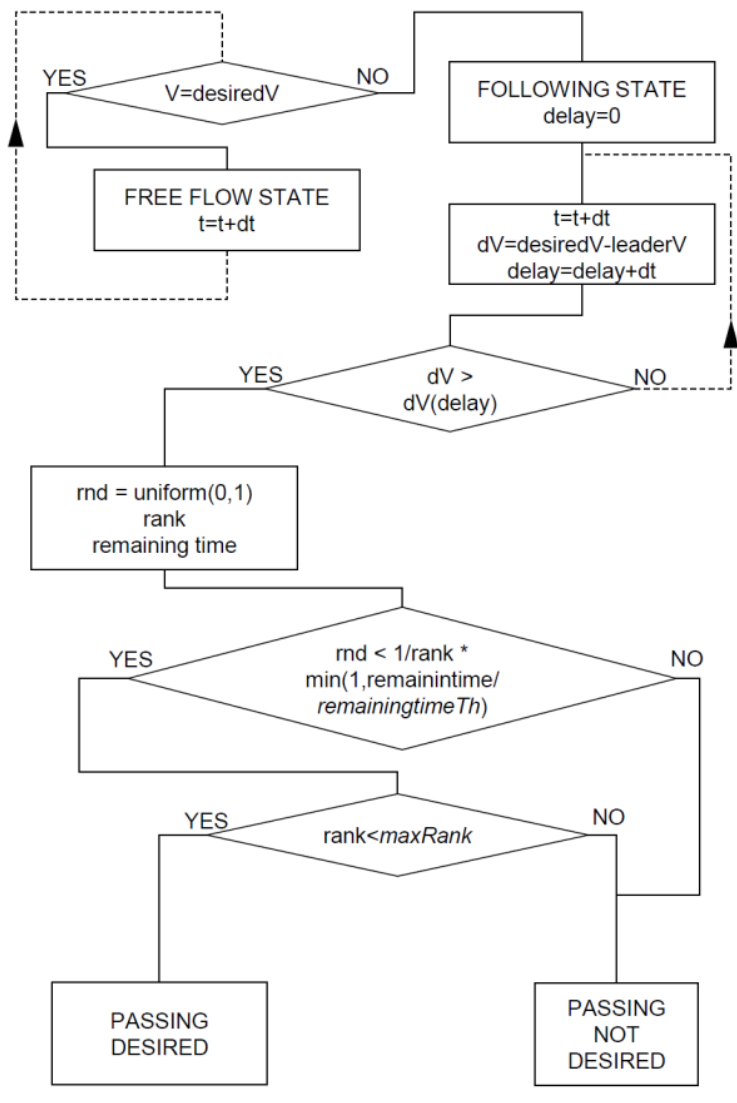

(a) Passing desire

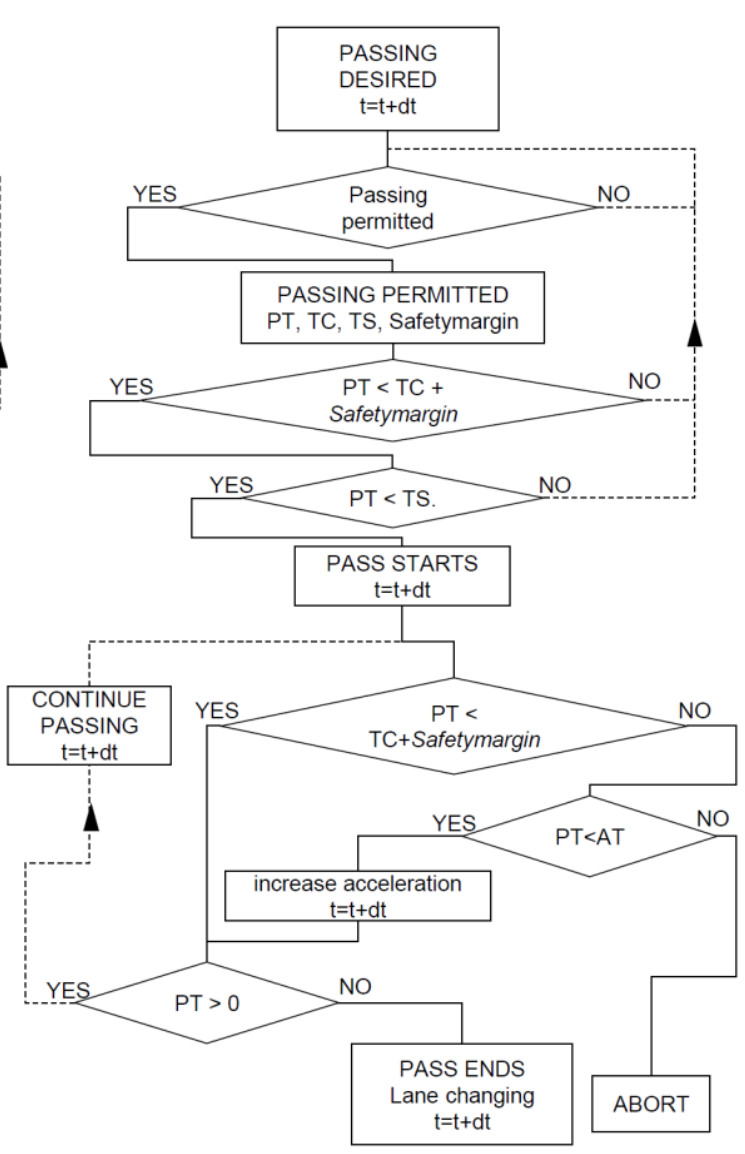

(b) Passing decisión and execution

Figure 3. Model flowchart

\section{Calibration}

The process of determining if a simulation model is close enough to the actual system is achieved through the calibration and validation (Barceló, 2010). The objective of the calibration is to find the values of the parameters of the model that are valid in a particular location. After the calibration process, the validation will answer the question whether the simulation model provides an accurate representation of the system under study or not.

After initial testing to detect and correct errors, the calibration of the passing model developed in this study was divided in two steps. A first step tested the model from the individual behavior point of view. This part verified that single driver decision and maneuvers were close enough to the observations. The second step compared the performance measures between the reality and the simulated model of four different passing zones and two different traffic volumes.

This procedure was selected due to the following reasons. Firstly, this provided a better control of the new model, in order to ensure that it is representative either at micro or macroscopic scale. Secondly, it was still not possible to use automatic calibration methodologies, as the model was in a development stage, being an independent module in Aimsun. Thirdly, the results of this procedure concluded which variables do not need further re-calibration and should be hidden for the user because their variation had low sensitivity on the results. Lastly, the manual calibration procedure resulted in an easier and better understanding of how the model works, although the accuracy of variable values might be slightly lower. 


\subsection{Microscopic scale calibration}

The calibration at microscopic scale was a comparison between observed and simulated passing behavior. In this section, the analysis of individual's behavior calibrated the value of the following parameters, which control passing decision and passing execution:

- Maximum Acceleration (Vehicle type): maximum acceleration rate of vehicles.

- Desired Speed (Vmax) (Vehicle type): desired free flow speed of vehicles.

- Speed acceptance factor $(\theta)$ (Vehicle type): factor that multiplies speed limit in order to allow exceeding it.

- Sensitivity factor for reduced car-following (RCF) (Experiment): explained in section 4.

- Passing vehicle speed enhancement (PVSE) (Experiment): explained in section 4.

- Speed difference threshold for enhanced passing vehicle speed (PVSETh) (Experiment): explained in section 4 .

- Safety margin for passing maneuver (minimum, maximum, mean and standard deviation of safetymargin) (Vehicle type): explained in section 4.

The values of these parameters were selected according to Aimsun default values (if the parameter already existed). This was the case of the three first parameters. The rest of parameters were selected based on the observed behavior (if they could be measured) or in a sensitivity analysis (if they could not be measured). The following sections develop the microscopic scale calibration of each output variable. The simulation scenario was a long passing zone (the longest of the macroscopic calibration step).

\subsubsection{Desired speed}

Desired speed is defined as the driver's selected speed without the effect of neither traffic nor highway alignment. Three parameters affect free-flow speed of a vehicle in Aimsun:

- Vmax : maximum desired speed.

- $\theta$ : Speed acceptance factor.

- Slimit: Speed limit.

The desired speed of a vehicle is Vdesired $=\min (V \max , \theta \cdot$ Slimit $)$.

The values of the three parameters were adjusted to the observed speed measurement data at $100 \mathrm{~km} / \mathrm{h}$ speed limit locations, both for heavy vehicles and light vehicles. Simulated and observed distribution were compared adjusting the Aimsun parameters using a least square method. 


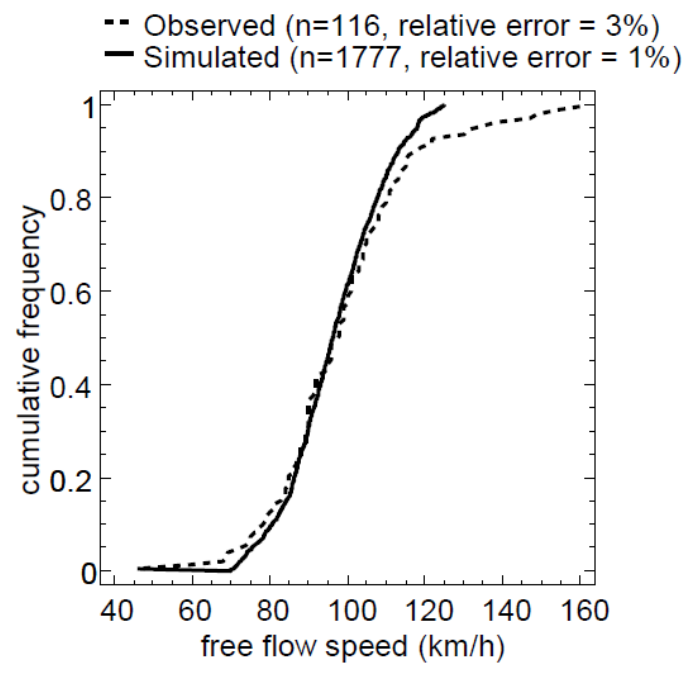

K-S test statistics:

Maximum distance $=0.07$

Admissible distance $=0.13$

(a) light vehicles

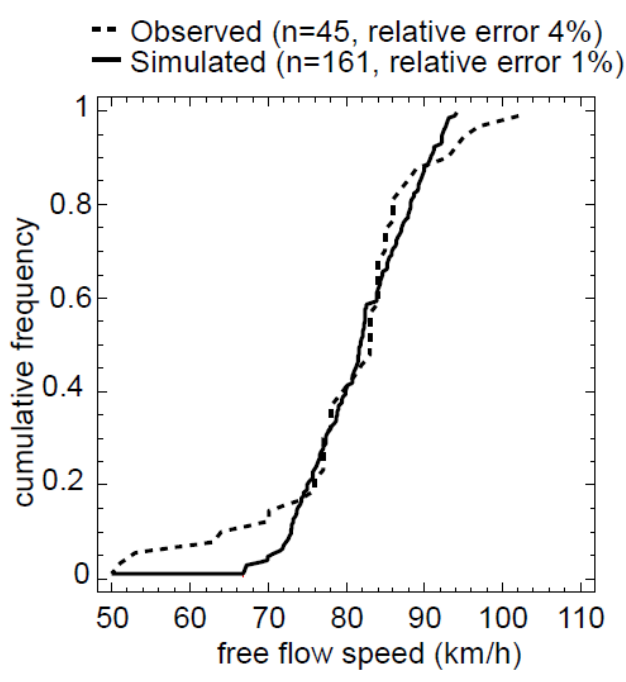

K-S test statistics:

Maximum distance $=0.12$

Admissible distance $=0.23$

Figure 4. Desired speeds

To compare the observed and simulated distributions shown in Figure 4, the non-parametric Kolmogorov Smirnov (K-S) test was carried out. The null hypothesis implies that both samples come from the same distribution. The test computes the maximum distance between the cumulative distributions of them, without assuming normality in none of them. In this case, the p-value was 0.678 (light vehicles) and 0.658 (heavy vehicles), so the null hypothesis could not be rejected at the $95 \%$ confidence level and there was not a statistically significant difference between the observed and the simulated speed distribution. In the Figure, the relative error is the amplitude of the confidence interval divided by the mean.

\subsubsection{Passing time (PT)}

Passing time $P T$ is the opposing lane occupation time. Passing time is the most significant passing maneuver variable, since it characterizes the time while the potential conflict with an opposing vehicle exists. The following analysis considers only simple maneuvers (one impeding vehicle).

The maximum vehicle acceleration was set as $4 \mathrm{~m} / \mathrm{s}^{2}$, according the Aimsun default values. A sensitivity analysis evaluated the influence of car-following reduction factor (RCF), PVSE and PVSETh. Decreasing RCF factor resulted in lower passing times. The value which minimized the difference between observed and simulated mean passing times was $R C F=0.65$. After selection of these parameters, simulated and observed passing time distributions were compared, as shown in Figure 5. On the other hand, the influence on passing time of PVSE and PVSETh was not significant. Their values were set according to the observed passing vehicle speed at the end of the maneuver $\left(t_{3}\right)$. This assumed that passing vehicle speed at $t_{3}$ was the equal to Aimsun defined desired speed for passing. This assumption justified selecting PVSETh of $15 \mathrm{~km} / \mathrm{h}$ (only in less than a $5 \%$ of observed maneuvers the speed difference was under $15 \mathrm{~km} / \mathrm{h}$ ). On the other hand, PVSE was set at 1.1 as only a $5 \%$ of passing maneuvers ended with a speed over $110 \mathrm{~km} / \mathrm{h}$ (being the speed limit equal to $100 \mathrm{~km} / \mathrm{h}$ ). 


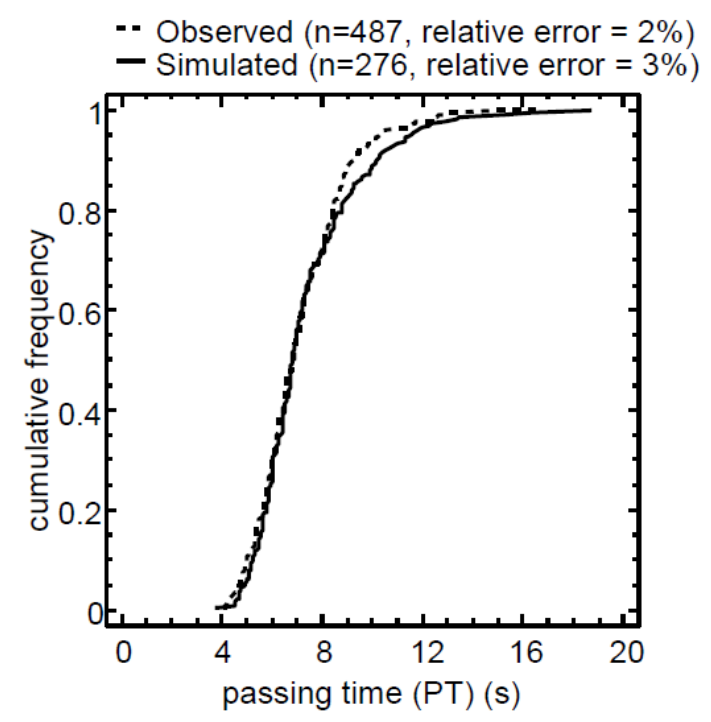

K-S test statistics:

Maximum distance $=0.07$

Admissible distance $=0.10$

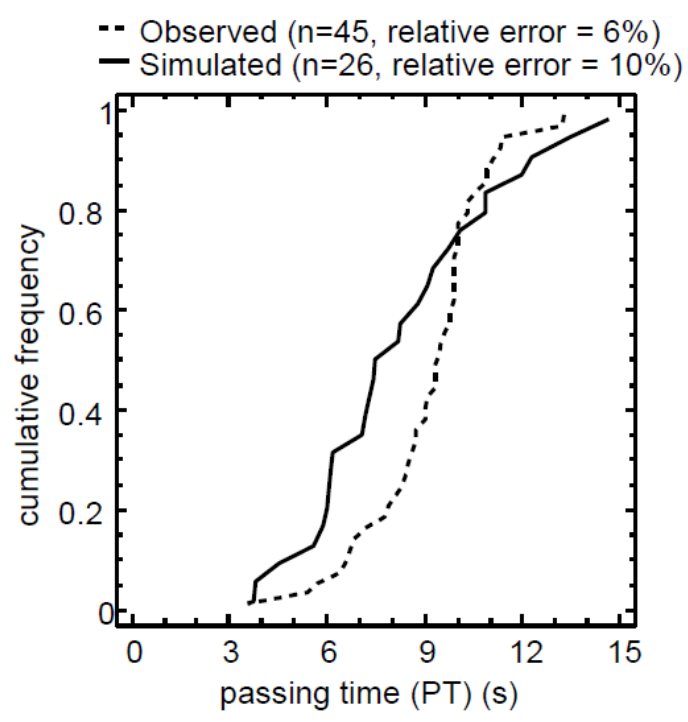

K-S test statistics:

Maximum distance $=0.35$

Admissible distance $=0.33$

(a) light vehicles

(b) heavy vehicles

Figure 5. Passing time

The K-S test concluded that there were no statistically significant differences at the $95 \%$ confidence level between observed and simulated passing times $P T$, in the case of light impeding vehicle (p-value 0.377 , accepting the null hypothesis). For heavy impeding vehicles, the observed and simulated times PT were different at the $95 \%$ level of confidence. As the only impeding heavy vehicles used in the data collection was a $16.5 \mathrm{~m}$ truck (upper length threshold in the simulation), the observed time distribution was slightly higher than the simulated.

\subsubsection{Gap acceptance}

The result of the passing decision is whether a gap in opposing traffic is accepted or not. A passing gap is the sum of passing time $(P T)$ and time until crossing with the next oncoming vehicle, if it exists (denoted by $t_{4}-t_{3}$, in Figure 1 ). The safetymargin parameter is for each individual driver the minimum acceptable time $t_{4}-t_{3}$. However, the safetymargin parameter cannot be measured in reality. A minimum value of $1 \mathrm{~s}$ was chosen based on previous research (Hassan et al, 1996, Harwood et al, 2010) and on minimum observed $t_{4}-t_{3}$. The maximum value was $10 \mathrm{~s}$, as longer safety margins are not reasonable even with very conservative drivers. Thereafter, mean and standard deviation were selected by adjusting simulated and observed critical gaps (those with a probability of acceptance equal to 0.5 ).

To compare simulated and observed passing decisions, a probit binary choice model was defined. This model (Brilon et al. 1999) assumes a critical gap $t_{c, d}$ for each driver according to equation 2. 


$$
t_{c, d}=t_{c}+\varepsilon_{d}
$$

where:

- $t_{c, d}$ : critical gap for driver $\mathrm{d}$.

- $t_{c}$ : mean critical gap.

- $\varepsilon_{d}$ : random error term.

The probability that a driver will accept a gap of size $t$ is calculated as shown in equation 3 .

Equation 3

$$
P a(t)=P\left(t>t_{c, d}\right)=\phi\left(\frac{t-t_{c}}{\sigma}\right)
$$

where:

- $P a(t)$ : probability of acceptance of gap $t$.

- $\phi$ : standard normal distribution.

- $t_{c}$ : mean critical gap.

- $\sigma$ : standard deviation of critical gap distribution.

Assuming that the random error term is normal distributed with mean zero, the probit model is constructed. A probit model was estimated for both simulated and observed gap sample. As a result, the critical gap distribution came from a normal distribution with mean $t_{c}$ and standard deviation $\sigma$. Both models were significant, according to Chi-Square tests, which compare the model with and without the selected variable (Gap). Adjusted R-squared coefficients were $46 \%$ (simulated) and $29 \%$ (observed). The mean critical gap for the observed sample was $17.9 \mathrm{~s}$, being the standard deviation equal to $8.6 \mathrm{~s}$. In the model, a mean safetymargin of $5 \mathrm{~s}$ provided the same simulated mean critical gap ( $17.8 \mathrm{~s}$ ), being their dispersion lower (standard deviation equal to $5,8 \mathrm{~s})$.

The previous analysis considered oncoming vehicle-limited and sight distance-limited passes. The difference between them is the visibility of the oncoming vehicle at the time the pass starts. Initially, this model is not able to distinguish both cases. In order to capture the different passing behavior in both cases, a sight distance factor (SDfactor) was defined in the model. The objective of this factor was to enlarge sight distance-limited gaps to have the same acceptance model as oncoming vehicle-limited gaps, but increasing their probability of acceptance. The size (in seconds) of sight distance-limited gaps in the reality is equal to the available sight distance at the decision station divided by the approaching relative speed (the sum of passing vehicle speed and opposing vehicle speed, assumed as speed limit) (Llorca et al. 2012).

Using the same probit model for observed gaps, but including an additional binary variable of visibility of opposing vehicles, the mean critical gap was $15.8 \mathrm{~s}$ gap for sight distance-limited maneuvers and $26.5 \mathrm{~s}$ for oncoming vehicle-limited maneuvers. This suggested that SDfactor was equal to its ratio, 1.75 .

\subsection{Macroscopic scale calibration}

This analysis started with the selection of four passing zones as calibration scenarios. The four passing zones were 265, 505, 1,050 and 1,270 m long, which covered a wide range of this variable. Moreover, two observed traffic volume levels were selected: working days (directional 
traffic flow of $140 \mathrm{vph}$ and $21 \% \mathrm{HV}$ ) and Sundays (directional traffic flows of $335 \mathrm{vph}$ and $2 \%$ $\mathrm{HV})$.

These scenarios belong to road 7 ( $\mathrm{N}-225$, as previously described in Table 1). Zones 1 and 2 (Z1 and $\mathrm{Z2}$ ) are at the same tangent, as well as $\mathrm{Z3}$ and $\mathrm{Z4}$. Z3 and Z4 are located west from $\mathrm{Z1}$ and $\mathrm{Z2}$, at a $500 \mathrm{~m}$ distance from them. Directional split is $50 \%$ each direction. Therefore, input traffic flow at the four zones is equal. Observed percent of followers depended on traffic volume (working day or Sunday). Table 3 summarizes traffic input observed variables.

Table 3. Calibration scenarios

\begin{tabular}{|c|c|c|c|c|c|c|c|c|c|}
\hline \multirow[b]{2}{*}{ Zone } & \multicolumn{4}{|c|}{ Working day } & \multicolumn{4}{|c|}{ Sunday } & \multirow[b]{2}{*}{$\begin{array}{c}\text { Available } \\
\text { Sight } \\
\text { Distance } \\
\text { (m) }\end{array}$} \\
\hline & $\begin{array}{c}\text { Volume } \\
\text { (vph) } \\
\text { (mean) }\end{array}$ & $\begin{array}{c}\text { Directional } \\
\text { split }\end{array}$ & $\% \mathrm{HV}$ (mean) & $\begin{array}{c}\text { \%FV } \\
\text { (mean) }\end{array}$ & $\begin{array}{c}\text { Volume } \\
\text { (vph) } \\
\text { (mean) }\end{array}$ & $\begin{array}{c}\text { Directional } \\
\text { split }\end{array}$ & $\begin{array}{c}\% \mathrm{HV} \\
\text { (mean) }\end{array}$ & $\begin{array}{c}\% F V \\
\text { (mean) }\end{array}$ & \\
\hline $\mathrm{Z1}$ & \multirow{4}{*}{140} & \multirow{4}{*}{$50 / 50$} & \multirow{4}{*}{$21 \%$} & $26 \%$ & \multirow{4}{*}{335} & \multirow{4}{*}{$50 / 50$} & \multirow{4}{*}{$2 \%$} & $51 \%$ & 400 \\
\hline $\mathrm{Z2}$ & & & & $26 \%$ & & & & $51 \%$ & 250 \\
\hline Z3 & & & & $26 \%$ & & & & $51 \%$ & 300 \\
\hline $\mathrm{Z4}$ & & & & $26 \%$ & & & & $51 \%$ & 250 \\
\hline
\end{tabular}

The sight distance at the end of each passing zone (ASD) was $400 \mathrm{~m}, 250 \mathrm{~m}, 250 \mathrm{~m}$ and $300 \mathrm{~m}$, in Z1, Z2, Z3, and Z4, respectively.

The macroscopic scale calibration compared first the following traffic variables with the reality: input traffic volumes and percent of followers. After that, the comparison of number of passes in the selected scenarios was used to calibrate the passing desire parameters (mindV, maxdV and delayTh).

This analysis used an aggregation time interval of $15 \mathrm{~min}$, according to Highway Capacity Manual recommendation (TRB, 2010). In these analyses maxRank value was equal to 2 , since passing maneuvers involving more than two vehicles were rarely detected (less than $1 \%$ of cases). On the other hand, according to Spanish driving regulations, simultaneous maneuvers are not permitted. Therefore, maxsimul was equal to the unit and the value of delaysimul did not affected the simulation. Lastly, since this study analyzed only single passing zones, the influence of remainingtimeTh was not considered. This parameter was zero in the simulations.

\subsubsection{Replications}

In a microsimulation model, most of input variables are random values. A replication is the simulation of a scenario taking particular values of the input variables. In order to characterize the system behavior, it is necessary to simulate a certain number of replications. The higher the variability of this behavior, the higher the number of replications needed to estimate its average.

Equation 4 estimated the minimum number of replications assuming that all variables came from normal distributions, as proposed by Hollander and Liu (2008). 


$$
n>\frac{Z_{0.95}^{2} \cdot s^{2}}{e^{2}}
$$

where:

- $n$ : minimum sample size.

- $Z_{0.95}$ : t-statistic, for a $95 \%$ confidence level it is equal to 1.96 .

- $s$ : sample standard deviation.

- $e$ : maximum error admitted. The confidence interval for the mean has a $2 e$ amplitude.

Table 4 summarizes the results of this estimation. For the simulation, the sample mean and sample standard deviation were obtained after an initial set of 10 replications. In the case of the number of passes, all passing zones were analyzed separately and the table only shows the worst case. Number of passes was converted to the equivalent 1-hour interval, as it presented a very high dispersion.

(a) Estimation of the error of the observed sample

\begin{tabular}{|c|c|c|c|}
\hline Traffic volume & $\begin{array}{c}\text { 15-min traffic } \\
\text { volume }\end{array}$ & $\begin{array}{c}\text { 15-min percent } \\
\text { followers }\end{array}$ & $\begin{array}{c}\text { 1-hour number of } \\
\text { passes }\end{array}$ \\
\hline Low & \multicolumn{3}{|c|}{$47^{*}$} \\
\hline High & $8 \%$ & $19^{*}$ \\
\hline $\begin{array}{c}\text { maximum relative error in } \\
\text { the observations (using } \\
\text { equation 4) }\end{array}$ & $8 \%$ & $17 \%$ (6 passes) \\
\hline
\end{tabular}

(b) Minimum number of replications to achieve a target $5 \%$ relative error

\begin{tabular}{|c|c|c|c|}
\hline Traffic volume & $\begin{array}{c}15-\text { min traffic } \\
\text { volume }\end{array}$ & $\begin{array}{c}\text { 15-min percent } \\
\text { followers }\end{array}$ & $\begin{array}{c}1 \text {-hour number of } \\
\text { passes** }\end{array}$ \\
\hline Low & $15^{* * *}$ & $15^{* * *}$ & $4^{* * *}$ \\
\hline High & $6 * * *$ & $6 * * *$ & $15^{* * *}$ \\
\hline \multicolumn{4}{|c|}{$\begin{array}{l}\text { *the values represent sample size } \\
* * \text { the target error in number of passes was } 4 \text { passes (lower than in the observations), as a } 5 \% \\
\text { would lead to a much higher number of simulations, especially in shorter zones where } \\
\text { number of passes is low. } \\
* * * \text { the values represent a minimum number of replications (using equation } 4 \text { ). }\end{array}$} \\
\hline
\end{tabular}

Table 4. Samples size and number of replications

After the results of Table 4, the number of replications was fixed at 15 . Once the 15 replications run, the error obtained from equation 4 was checked again.

Table 4 showed similar and reasonable maximum errors in the estimation of the mean of the macroscopic variables. The objective of the next sections was to adjust the simulated variables to the observed equivalent values.

\subsubsection{Traffic input}

Aimsun traffic volume value corresponds to the mean one-way traffic input volume at the modeled highway in vph. Headways between consecutive vehicles are randomly generated using an exponential function. Consequently, the actual vehicles entering the network are also randomly distributed. 
The first step of the calibration compared the 15-min one-way traffic volume distributions of observed and simulated conditions. The K-S test showed no difference between observed and simulated distributions (accepting the null hypothesis at the $95 \%$ confidence level with $p$-values of 0.643 and 0.507 , on working days and Sundays, respectively). This step did not involve any change in the model parameters.

\subsubsection{Platooning}

Vehicles form platoons while driving on two-lane rural highways, due to their speed dispersion. Faster vehicles enter in platoons behind slower vehicles, while passing is forbidden, limited by opposing traffic or simply not desired. The percent followers entering a passing zone depends on the geometry, operating speed, marking, and signing upstream the location. However, the calibration process carried out in this study considered only single passing zones. Therefore, the highway upstream with its passing zones was substituted by one no-passing zone segment.

The no-passing zone segment length depended on the traffic volume, and was fixed to generate the same percent followers (either the mean or the frequency distribution) entering the simulated passing zones as in the observed scenarios. In this case, the segment was $2300 \mathrm{~m}$ for working day conditions and $2800 \mathrm{~m}$ for Sunday conditions, since the percent followers was different in both cases. In this analysis, a vehicle was inside a platoon (in following-state) if its headway was under $3 \mathrm{~s}$, according to common Highway Capacity Manual criterion (Transportation Research Board, 2010). K-S test showed that there were no differences between observed and simulated samples (accepting the null hypothesis at the $95 \%$ confidence level with p-values of 0.133 and 0.070 , on working days and Sundays, respectively). This step only modified the length of the adjacent no-passing sections, without affecting the other passing model parameters.

\subsubsection{Passing maneuvers}

The previous steps have generated the traffic flow entering the selected passing zones, which was not statistically different from the observed. Then, it was verified whether the two-way passing model simulated realistically passing maneuvers.

This analysis compared the 1-hour number of passing maneuvers in single passing zones between the Aimsun model and the observations. Only completed maneuvers were considered. Aborted maneuvers represented less than $1 \%$ of cases, both in simulation and in the reality. The objective was to calibrate the parameters delayTh, $\operatorname{maxdV}$ and mindV that provided the minimum difference on number of completed passing maneuvers.

In order to obtain the value of the parameters that minimize the error in the number of passes in each passing zone, the root mean square error (RMSE) (Equation 5) was proposed as optimization criterion, as proposed by Hollander and Liu (2008). 


$$
R M S E=\sqrt{\frac{\sum_{i}^{n}\left(N P_{o b s, i}-N P_{s i m, i}\right)^{2}}{N}}
$$

where:

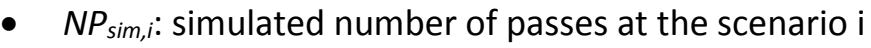

- $N P_{o b s, i:}$ observed number of passes at the scenario $\mathrm{i}$

- $\quad N$ : number of calibration scenarios

A total of $3 \times 3 \times 3$ calibration cases were simulated: three values of each parameter. The parameter delayTh was 180, 240, $300 \mathrm{~s}$, mindV 5, 10, $15 \mathrm{~km} / \mathrm{h}$ and $\operatorname{maxdV} 30,35$ and $40 \mathrm{~km} / \mathrm{h}$.

The result of simulating each calibration case was the number of passes in eight passing zones (four zones with two traffic levels). These values were used to calculate RMSE. The calibration case with lower RMSE was selected, as shown in Figure 6.
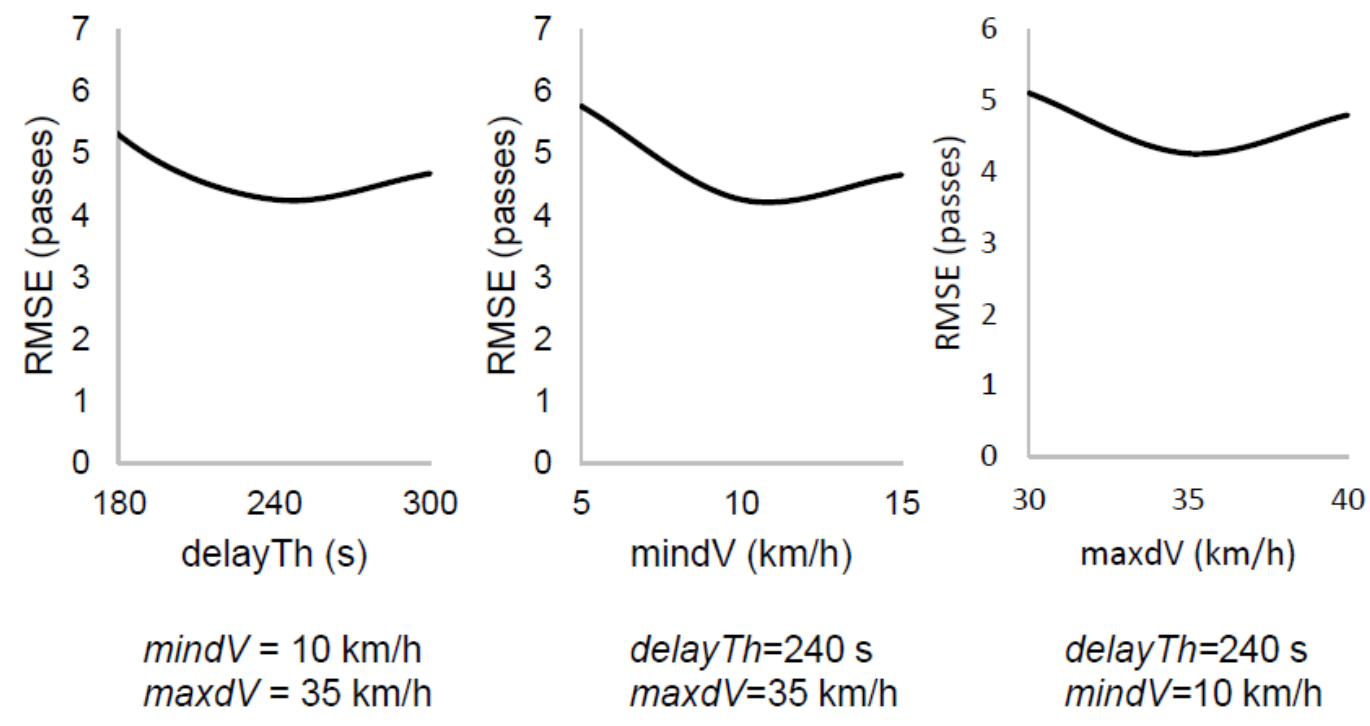

Figure 6. Calibration of passing desire parameters

As a result, the values of the parameters were delayTh $=240 \mathrm{~s}, \min d V=10 \mathrm{~km} / \mathrm{h}$ and $\operatorname{maxdV}=$ $35 \mathrm{~km} / \mathrm{h}$. RMSE was 4.2 passing maneuvers.

\section{Validation}

The objective of the validation is to apply the calibrated model to other scenarios. This step provides information about the ability of the model to represent a variety of situations, and not only the particular locations used for calibration.

The validation process tested the calibrated model in four different passing zones: with low (Z7) and high traffic volume (Z5), short (Z8) and long (Z6) passing zones and with different directional splits, percent followers and percent heavy vehicles. Table 5 summarizes the validation scenarios and the results. 
Table 5. Validation scenarios and results

\begin{tabular}{|c|c|c|c|c|c|c|c|c|c|c|}
\hline \multirow[b]{2}{*}{ ZONES } & \multicolumn{7}{|c|}{ Scenarios characteristics } & \multicolumn{3}{|c|}{ Validation results } \\
\hline & $\begin{array}{c}\text { Volume } \\
\text { (vph) } \\
\text { (mean) }\end{array}$ & $\begin{array}{c}\text { Directional } \\
\text { split } \\
\text { (mean) }\end{array}$ & $\begin{array}{c}\text { \%HV } \\
\text { (mean) }\end{array}$ & $\begin{array}{c}\text { \%FV } \\
\text { (mean) }\end{array}$ & $\begin{array}{c}\text { Available } \\
\text { Sight } \\
\text { Distance } \\
(\mathrm{m})\end{array}$ & $\begin{array}{l}\text { Passing } \\
\text { zone } \\
\text { length } \\
(\mathrm{m}) \\
\end{array}$ & $\begin{array}{c}\text { Posted } \\
\text { speed } \\
\text { limit } \\
(\mathrm{km} / \mathrm{h})\end{array}$ & $\begin{array}{c}\text { 1-hour } \\
\text { observed } \\
\text { number of } \\
\text { passes }\end{array}$ & $\begin{array}{c}\text { 1-hour } \\
\text { simulated } \\
\text { number of } \\
\text { passes }\end{array}$ & Difference \\
\hline $\mathrm{Z5} \mathrm{(Rd.} \mathrm{8)}$ & 314 & $42 / 58$ & $6 \%$ & $29 \%$ & 200 & 895 & 80 & 5.6 & 2.8 & 2.8 \\
\hline Z6 (Rd. 1) & 164 & $52 / 48$ & $18 \%$ & $34 \%$ & 550 & 1,765 & 100 & 25.0 & 23.4 & 1.6 \\
\hline $\mathrm{Z7}$ (Rd. 6) & 70 & $50 / 50$ & $16 \%$ & $30 \%$ & 200 & 540 & 90 & 1.0 & 0.5 & 0.5 \\
\hline $\mathrm{Z8} \mathrm{(Rd.} \mathrm{3)}$ & 145 & $50 / 50$ & $16 \%$ & $28 \%$ & 200 & 265 & 100 & 0.5 & 1.1 & -0.7 \\
\hline & & & & & & & & & RMSE & 1.6 \\
\hline
\end{tabular}

The validation started with the definition of input traffic flow according to observations. The next step established the no-passing zone length upstream to the analyzed passing zones. The same desired speed and speed acceptance distributions were considered, although posted speed limit varied in each validation zone.

Once entering flows were equivalent to the observations, the number of passes was estimated using the calibrated model. The number of replications was fixed again in 15. Table 5 shows the results.

The results of the validation showed that this model may also be applied to conditions significantly different to the calibration scenarios. The RMSE obtained was lower than in the calibration scene, having a value of 1.6 passes.

\section{Conclusions}

This study has developed a microsimulation model for two-way two-lane rural highways. The model incorporated 14 parameters, which allow the user to include and analyze the effect of human factor, road geometry and vehicle characteristics on car-following and passing maneuvers. Every part of the model was created based on the observation of car-following and passing maneuvers on a sample of 10 rural highways in Spain.

The study obtained the following conclusions:

1. Characterization of 1,752 maneuvers on 10 two-lane rural highways using two methodologies. It included both a microscopic description (based on passing time, passing speeds and gap acceptance decisions) and a macroscopic description (traffic flows, percent followers and number of passes). The data collection covered a wide range of passing zone lengths (100 to $1,855 \mathrm{~m}$ ), design speeds (70 to $120 \mathrm{~km} / \mathrm{h}$ ) and traffic flows (one-way volumes from 52 to $740 \mathrm{vph}$ ).

2. Development of a modified car-following and a passing model for Aimsun microsimulation software. This model was divided into three stages: passing desire, passing decision and passing execution. The major innovations of this model in comparison with most of previous models, that reflect the observed driver behavior, were:

a. Global passing desire function which incorporates both the time spent following and the speed difference between desired speed and leader speed.

b. Effect of available sight distance on the gap acceptance process. Besides, the possibility to distinguish passing driver behavior facing sight distance-limited and oncoming vehicle-limited maneuvers. 
c. Possibility that passing vehicles increase their speed while passing over free flow desired speed. This speed enhancement is permitted by Spanish traffic regulations.

d. Effect of reducing passing desire when the remaining time until the end of the two-lane rural road segment is reduced.

e. Impact of reducing passing desire if the number of vehicles to pass increases.

3. Sensitivity factor to reduce car-following safety distance prior passing.Calibration of the model. The values of the model parameters were calibrated comparing the simulation results with the observational data. This study focused only on single passing zones. Calibration was divided in two stages:

a. Microscopic scale, to adjust parameters affecting individual desired speeds, passing times and gap acceptance decisions. The results showed an adequate characterization of passing behavior, based on the comparison of simulated and observed frequency distributions and binary choice models.

b. Macroscopic scale, to adjust parameters affecting passing desire. The results show that the model adequately estimated the performance measures. The root mean square error in the estimation of 1-hour number of passes was 4.2.

The conclusions of this calibration showed also the sensitivity of the parameters in the estimation of either microscopic or macroscopic passing variables.

4. Validation of the model. The model was applied to four other scenarios with a wide passing zone length and traffic flow range. The results provided a root mean square error of 1.6 in the estimation of the number of passes. This supported the validity of the model in the estimation of the number of passes in different types of passing zones.

The results of the calibration and validation for this model depended on the collected data; so, any extrapolation to other conditions and scenarios must be taken with care. Besides, the model was implemented and calibrated on single passing zones, so the interaction among passing zones and no-passing zones was not investigated.

The result of this study is a modified car-following and a passing model implemented in Aimsun software, which can estimate adequately the operation of single passing zones. In the future, a more complex calibration will be performed using longer two-lane rural road segments with multiple passing zones. A full sensitivity analysis should also be conducted. The comparison with data from other regions will contribute to set the value of certain parameters, improving model simplicity.

\section{Acknowledgements}

Data collection was part of the research project "Desarrollo de modelos de distancias de visibilidad de adelantamiento", funded by the Spanish Ministry of Economy and Competitiveness, with reference number TRA2010-21736. Authors wish to thank Spanish General Directorate of Traffic, Spanish Ministry of Public Works, Valencia Regional Department of Transport and Valencia Province Road Department, for their collaboration in the field study.

\section{References}

American Association of State Highway and Transportation Officials (AASHTO), 2004. A policy on geometric design of highways and streets, 5th edition. American Association of State Highway and Transportation Officials, Washington DC, USA. 
American Association of State Highway and Transportation Officials (AASHTO), 2011. A policy on geometric design of highways and streets, 6th edition. American Association of State Highway and Transportation Officials, Washington DC, USA.

Barceló, J., 2010. Models, Traffic Models, Simulation and Traffic Simulation. In: Barceló, J. (Ed.), Fundamentals of Traffic Simulation, Springer Science+Business Media, New York, NY, USA, pp1-62.

Bessa, J.E., Setti, J.R., 2011. Derivation of ATS and PTSF Functions for Two-Lane, Rural Highways in Brazil. In: 6th International Symposium on Highway Capacity and Quality of Service, Stockholm, Sweeden, Proccedia - Social and Behavioral Sciences, 16, 228-292.

Brilon, W.; Brannolte, U.: Simulation des Verkehrsablaufs auf Landstraßen. Schriftenreihe "Forschung Straßenbau und Straßenverkehrstechnik" des BMV, Heft 239, Bonn, 1977

Brilon, W., Koenig, R., Troutbeck, R.J., 1999. Useful estimation procedures for critical gaps, Transportation Research Part A: Policy and Practice, 33(3-4), 161-186.

Carlson, P.J., Miles, J.D., Johnson, P.K., 2006. Daytime high-speed passing maneuvers observed on rural two-lane, two-way highway findings and implications, Transportation Research Record, 2006, 9-15.

Dey, P., Chandra, S., Gangopadhyay, S., 2008. Simulation of Mixed Traffic Flow on Two-Lane Roads, Journal of Transportation Engineering, 134(9), 361-369.

Farah, H. 2011, Age and gender differences in overtaking maneuvers on two-lane rural highways. Transportation Research Record, 2248, 30-36.

Farah, H., Toledo, T., 2010. Passing behavior on two-lane highways. Transportation Research Part F: Traffic Psychology and Behaviour, 13(6), 355-364.

Federal Highway Administration FHWA, 2003. Manual on Uniform Traffic Control Devices (MUTCD), Federal Highway Administration, Washington DC, USA.

Gipps, P.G., 1981. A behavioural car-following model for computer simulation, Transportation Research Part B: Methodological, 15(2), 105-111.

Ghods, A.H., Saccomanno, F., 2013. Safety Implications of Truck/Car Speed Limits for Two-Lane Highway Operations. In: Transportation Research Board 92nd Annual Meeting, Washington DC, USA.

Harwood, D., May, A., Anderson, I., Leiman, L., Archilla,R., Capacity and Quality of Service of Two-Lane Highways. National Cooperative Highway Research Program, Transportation Research Board, Washington DC, USA.

Harwood, D.W., Gilmore, D.K., Richard, K.R., 2010. Criteria for passing sight distance for roadway design and marking. Transportation Research Record, 2195, 36-46.

Hassan, Y., Easa, S.M., Abd El Halim, A.O., 1996. Passing sight distance on two-lane highways: Review and revision, Transportation Research Part A: Policy and Practice, 30(6), 453-467.

Hegeman, G., Tapani, A., Hoogendoom, S., 2009. Overtaking assistant assessment using traffic simulation. Transportation Research Part C: Emerging Technologies, 17(6), 617-630. 
Hoban, C. J., R. J. Shepherd, G. J. Fawcett and G. K. Robinson, 1991. A Model for Simulating Traffic on Two-Lane Rural Roads: User guide and manual for TRARR version 3.2. Australian Road Research Board, Victoria.

Hollander, Y.; Liu, R., 2008. The principles of calibrating traffic microsimulation models. Transportation, Springer Science and Business Media, LLC, 35, 347-362.

Ištoka Otković, I., Tollazzi, T., Šraml, M., 2013. Calibration of microsimulation traffic model using neural network approach, Expert Systems with Applications, 40(15), 5965-5974.

Jenkins, J. M., Rilett, L. R., 2004. Application of distributed traffic simulation for passing behavior study, Transportation Research Record, 1899, 11-18.

Jie, L., Van Zuylen, H.V., Chen, Y., Viti, F., Wilmink, I., 2013. Calibration of a microscopic simulation model for emission calculation, Transportation Research Part C: Emerging Technologies, 31, 172-184.

Khoury, J.E., Hobeika, A.G., 2012. Integrated Stochastic Approach for Risk and Service Estimation: Passing Sight Distance Application, Journal of Transportation Engineering, 135(5), 571-579

Kim, J., Elefteriadou, L., 2010. Estimation of capacity of two-lane two-ways highways using simulation model. Journal of Transportation Engineering, 136(1), 61-66

Li, J., Washburn, S.S., 2011. Implementing Two-Lane Highway Simulation Modeling into CORSIM1. In: 6th International Symposium on Highway Capacity and Quality of Service, Stockholm, Sweeden, Proccedia - Social and Behavioral Sciences, 16, 296-305.

Llorca, C. Moreno, A.T., García, A., Pérez-Zuriaga, A.M., 2012. New approach on passing gap acceptance. In: Transportation Research Board 91st Annual Meeting, Washington DC, USA.

Llorca, C. Moreno, A.T., García, A., Pérez-Zuriaga, A.M., 2013a. Daytime and Nighttime Passing Maneuvers on Two-Lane Rural Road in Spain, Transportation Research Record, 2358, 3-11.

Llorca, C. Moreno, A.T., García, A., Pérez-Zuriaga, A.M., 2013b. Influence of age, gender and delay on overtaking dynamics, IET Intelligent Transport Systems, 7(2), 174-181.

Llorca, C., García, A., 2011. Evaluation of passing process on two-lane rural highways in Spain with new methodology based on video data. Transportation Research Record, 2262, 42-51.

Moreno, A.T., Llorca, C., García, A., Pérez-Zuiraga, A.M., 2013. Operational Effectiveness of Passing Zones Depending on Their Length and Traffic Volume, Transportation Research Record, 2395, 57-65.

Polus, A., Livneh, M., Frischer, B. 2000. Evaluation of the passing process on two-lane rural highways. Transportation Research Record, 1701, 53-60.

Stevanovic, A., Stevanovic, J. Kergaye, C., 2013. Optimization of traffic signal timings based on surrogate measures of safety, Transportation Research Part C: Emerging Technologies, 32, 159178.

Tapani, A., 2005. Versatile model for simulation of rural road traffic. Transportation Research Record, 1934, 169-178. 
Transport Simulation Systems, 2013. TSS Aimsun Version 8.0.2 User Manual. Transport Simulation Systems, Barcelona, Spain.

Transportation Research Board, 2010. Highway Capacity Manual, Transportation Research Board, Washington DC, USA.

Valencia Alaix, V.G., García, A. 2010. Procedures to facilitate passing on conventional highways by means of simulation. In: 4th International Symposium on Highway Geometric Design, Valencia, Spain.

\section{List of Tables}

Table 1. Data collection sites

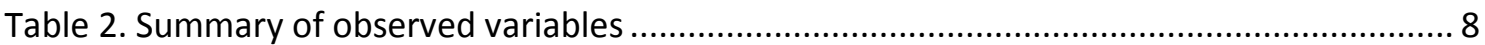

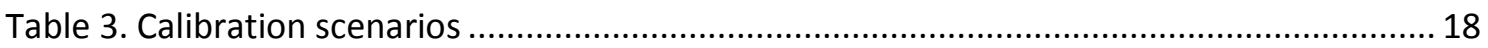

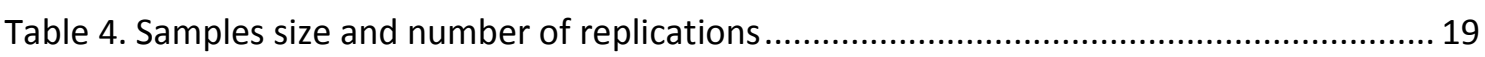

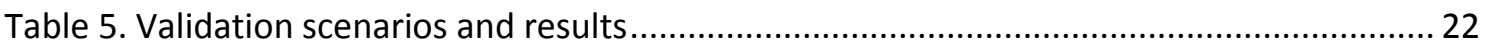

\section{List of figures}

Figure 1. Field study layout and description of the passing maneuver ...................................... 6

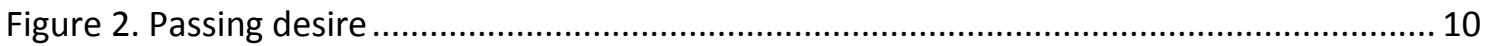

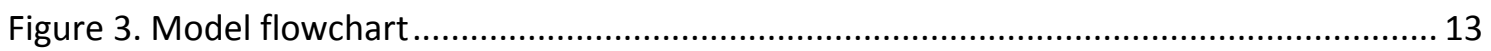

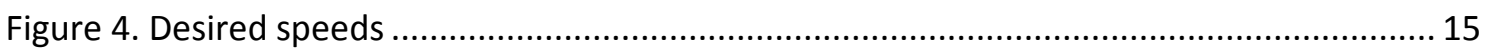

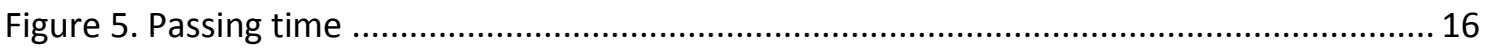

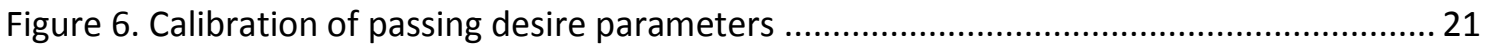

